\title{
CONTROVERSIES
}

\section{Genetic ties and genetic mixups}

\author{
T H Murray, G E Kaebnick
}

J Med Ethics 2003;29:68-69

$1 \mathrm{n}$ a recent case in Great Britain, a couple described as "white" underwent in vitro fertilisation and gave birth to twins described as "black". In the sense of a fair adjudication of this particular case, serving justice requires a thick description and a sensitive understanding of the relevant facts. We have only a few facts, but they may be sufficient to serve justice in this first sense.

We are told that the couple wants to keep the twins. We are told further that British law holds that the woman giving birth is to be regarded as the legal mother (although the father's paternity is not conclusively established by the fact of his marriage to the babies' mother). Finally, we are told that DNA testing has established that the gestational mother is also the genetic mother of these infants. Her husband, whose sperm were supposed to be used to fertilise his wife's eggs, is not the genetic father. A black couple was also undergoing IVF at the same clinic; it may be that this man's sperm were used by mistake.

We know enough to reach a defensible decision in the case. The couple caring for these children has contributed a half share of the children's genes, and the woman was also the gestational mother, so they have at least an equal argument from biology. Their intention was to have these children and they also wish to raise them; they went through the rigours of IVF, and are willing to take on the responsibility of parenthood. Since the children were born, furthermore, they have shouldered the hard work of parenthood. We don't know their particular circumstances; perhaps they've had help from family or others; but in all likelihood they've had an ample share of sleep deprived nights, soiled nappies, and exhausted days.

Unless other dramatic facts emerged to reverse our perceptions of the case, it appears that justice is served by allowing the babies to stay with this couple.

But then there is Justice.

In its broad sense, Justice requires a fair set of laws, institutions, and practices on which people can rely and that can be used both to guide public policy and to resolve disputes. The case at hand is most troubling for the challenges to Justice it reveals. Two difficulties stand out. First is the upheaval in traditional ideas and practices for assigning parenthood caused by assisted reproductive technologies (ARTs). Lying close beneath the surface of this disturbance are our understandings of the possible meanings of parenthood. Second is the unsettling suggestion that practices in infertility clinics may not be as scrupulous and trustworthy as we would like to believe.

\section{MEANINGS OF PARENTHOOD}

It may have been simpler in eras past to associate parents with children, but it was never without complications. The "seven seas" rule assumed that the husband of the woman giving birth was the child's father-unless he was upon the seven seas during the interval in which conception must have occurred. The possibility that the woman giving birth was not the child's genetic mother was, pardon the word, inconceivable. That a man and woman could be the genetic parents of a child carried by another woman was impossible before IVF. That a woman's egg might be fertilised by a man who was not her sexual partner-unbeknownst to any of the parties! - was likewise unimaginable.

Assisted reproductive technologies have forced us to create new laws and new social practices to protect the interests of the various parties and to prevent or resolve disputes that inevitably arise. Assisted reproductive technologies have also compelled us to think more clearly about what it means to be a parent. Three possible meanings of parenthood snap into focus: parenthood as biology; parenthood as intention, and parenthood as childrearing.

Biology includes both genes and gestation. The child born to a woman who is also its genetic mother is her biological child in both senses. The man supplying the sperm is the biological father. So much is beyond dispute. The ethical and policy implications, however, turn on what significance biological parenthood should carry. Judging by certain contemporary practices, biology sometimes matters very little: consider a child who was conceived by artificial insemination with sperm from an anonymous man. Yet at other times we give it enormous weight.

The second meaning of parenthood is intentionality. This woman and this man intend to have this child. Parenthood as intention is commonly linked to biology, but it need not be. The use of other people's ova, sperm, or womb can attenuate or sever the biological tie. Nor is there any guarantee that the child's conception or birth is intended by its biological progenitors. Attitudes among biological parents range from unmitigated joy through resignation to fierce resentment.

Third and last is the concept of rearing parenthood. The emphasis here is on providing the care-physical, emotional, financial-that the child needs in order to survive and flourish. Rearing parents may be attached to the child by biology; but the ancient practice of adoption shows that people can be parents in the complete absence of a biological tie. The link between intention and rearing is strong, but rearing parents can be resigned or resentful whether or not they are also biological parents.

The relationship between parent and child is best understood in terms of mutuality, rather than in terms of property or stewardship, as it often has been. ${ }^{1}$ Mutuality is a property of an actual relationship, not merely a biological tie. Mutuality acknowledges the significance of that relationship for the flourishing of both child and parent, and not merely the duty to provide competent care, which is the essence of stewardship. Furthermore, mutuality does not insist that the parent have intended to bring the relationship into existence; only that the parent now intends to care for and love the child.

If we take mutuality seriously as a model of the parent/child relationship, we are obliged to give great weight to rearing parenthood-both for the child's wellbeing, but also for the wellbeing of the rearing parents. When all three meanings of parenthood are more or less aligned, as in this case, ethics and policy are not called upon to decide amongst them. The tough questions come when we are pulled in different directions, and perhaps particularly when rearing parenthood appears to be at odds with biological parenthood. Are a man and woman 
who raise a child the "real parents" of that child even if the child was conceived with a donated egg and sperm? Should we regard a man as the "real father" of a child if his sperm was collected posthumously and used to inseminate his wife when there is no evidence that he intended to have his sperm used to conceive a child? We cannot avoid confronting the implications of these three meanings of parenthood for disputes such as the one discussed here, for public policy towards ARTs, and for the future of parents and children.

\section{PREVENTING AND CATCHING BLUNDERS}

Although these different conceptions of parenthood do not pull in different directions in this case, they bear on related concerns this case broaches about IVF and other ARTs. Very likely, there are other cases involving mixups that have gone undiscovered. This case would almost certainly not have come to light had both couples been of the same race. In other mixups, misattributed genetic paternity may not have been discovered because the child passed what has sometimes been called the "bald eagle test" of paternity - the child just looked like the putative parents. We must consider what policy responses are appropriate to prevent, catch, and correct these blunders. In fashioning these policy responses, we should be guided by our understanding of what parenthood means.

One point needs little argument: clinics must act competently. They need to review and tighten their procedures so that samples do not get crossed in the first place. Half cleaned pipettes and incorrectly labelled test tubes are simply unacceptable. Even if parenthood is not determined by biology, still, many people consider a biological connection with their children very desirable, and in most cases those who seek the services of infertility clinics consider a biological connection important. The case description suggests there is some movement among infertility clinics to prevent this sort of mishap.

More complicated are questions about what measures should be taken to catch and correct blunders that nonetheless occur. One possible policy response involves services that might be offered to catch mistakes before pregnancy. The case description mentions, for example, that a Melbourne clinic plans to offer prospective parents what appears to be preimplantation genetic diagnosis.

If we believe that parenthood is chiefly a rearing relationship, how should we think about services meant to confirm the existence of anticipated biological ties? For one thing, a genetic relationship can be an important aspect of parenthood even if parenthood is fundamentally a psychosocial phenomenon. The presence of a genetic relationship can give additional dimensions along which the parents' and child's relationship can range. It allows them to drawhowever tentatively-connections between the child and other family members that may give the child a sense of identity and of shared experience with family members. ${ }^{2}$ Another, more prosaic benefit is that children who are genetically related to their parents have easier access to the medical histories of their genetic relatives, and so a better understanding of their own medical risks as they mature.
If there are at least plausible arguments in favour of permitting people to use genetic testing to catch mistakes before an embryo is even implanted, what about using it to uncover blunders made in years past? (The risks and the cost of such preimplantation genetic testing would also need to be considered.) If adults who now have established relationships with children conceived through IVF also want genetic paternity testing-just to make sure that the child is biologically theirs, should they be permitted, or even encouraged, to obtain genetic paternity testing?

We should ask why parents might desire or come into possession of such information. It may happen inadvertently as an outcome of testing for a health related reason-for example, looking for a compatible organ or tissue donor or, perhaps more commonly in the future, in a search for alleles that alter disease risks. Or one or both parents may seek to confirm-or disconfirm-a genetic tie to the child. Sadly, most such cases are motivated by disputes between the parents-over child support, visitation rights, or the like. Rarely if ever is the child's welfare at the heart of such testing.

If we accept that parenthood is fundamentally a rearing relationship, not a biological one, then our public policy towards testing for genetic ties should promote those uses that support parenthood as rearing and discourage uses that undermine child/parent relationships built on care and trust. A man, for example, who has effectively undertaken parental obligations by assuming the role of rearing parent, but whose relationship with the child's mother has been shattered, can certainly be compelled to offer ongoing financial support. Parenthood as rearing relationship also supports such a parent's interest in continuing an emotional relationship with the child, whether or not a genetic tie exists.

Doing justice in this case is clear: the twins should remain in the care of the parents who have loved and raised them. Doing "Justice" in the broader sense requires thinking carefully about the different meanings of parenthood, and ensuring that our clinical practices as well as our policies and laws support the flourishing of children and parents. ${ }^{3}$

\section{Authors' affiliations \\ T H Murray, G E Kaebnick, The Hastings Center, Garrison, New York, USA}

Correspondence to: Dr G E Kaebnick, The Hastings Center, 21 Malcolm Gordon Road, Garrison, New York, 10524, USA:

kaebnick@thehastingscenter.org

Accepted for publication 21 November 2002

\section{REFERENCES}

1 Murray TH. The worth of a child. Berkeley, CA: University of California, 1996.

2 See Nelson JL. Genetic narratives: biology, stories, and the definition of the family. Health Matrix 1992;2:71-83, at 81.

3 Murray TH. What are families for? Getting to an ethics of reproductive technology. Hastings Cent Rep 2002;32:41-5. 